\section{La philía y la guerra en la filosofía de la historia epicteteana}

\section{Francisco Miguel Ortiz Delgado}

Universidad Autónoma Metropolitana, México.

Recibido el 8 de septiembre de 2017; aceptado el 30 de marzo de 2018.

\begin{abstract}
Resumen
El presente artículo estudia el uso filosófico que Epicteto realiza de varios pasajes de la historia de Grecia y de Roma. Los conceptos de amor-amistad (philía) y de conveniencia (sumphéron) personal secundan al filósofo para explicar el motivo de que la felicidad (eudaimonía) no se haya alcanzado para el ser humano a través de toda la historia. Toda guerra y contienda (pólemos) histórica, como la de Troya, las Médicas o la del Peloponeso, es provocada por errores epistemológicos-morales derivados del desconocimiento del lugar correcto para colocar el sumphéron, tal lugar correcto sólo es la "capacidad racional" personal (proháiresis). Esta explicación causal de los actos humanos incorrectos y viciosos, de los que está llena toda la historia y que destruyen la philía entre los pueblos y provocan pólemos, constituye una auténtica filosofía de la historia epicteteana. No obstante, esos actos viciosos tienen su justificación plena en el superior nivel Cósmico ya que están pre-determinados y ordenados por la Providencia-Dios. Lo anterior dicho lleva a que podamos observar que la filosofía de la historia estoica, en particular la epicteteana, es análoga a ciertos sistemas especulativos modernos en torno al devenir histórico como el viqueano o el hegeliano.
\end{abstract}

\section{Philia and War in the Epictetan Philosophy of History}

\begin{abstract}
The present article studies the epictetean philosophical use of some passages of the Greek and Roman history. The concepts of love-friendship (philía) and personal convenience (sumphéron) second the philosopher to explain why happiness (eudaimonia) has not been reached by the human being in all history. All historical war or strife (pólemos), such as the Trojan, the Medics and the Peloponnesian wars, is provoked by epistemological-moral mistakes derived from the ignorance of which is the correct place to put the sumphéron; such correct place is only the personal "rational capacity" (proháiresis). This causal explanation of the incorrect and vicious human actions, of which history is full and which destroy the existent philia between nations and provoke pólemos, constitutes an authentic epictetean philosophy of history. Nevertheless,
\end{abstract}

\section{Palabras clave}

Filosofía de la historia Epicteto Estoicismo Ética

Amor-amistad

Guerra

\section{Keywords}

Philosophy of history Epictetus Stoicism Ethics Love-friendship War 
1. Este artículo está inspirado y parcialmente basado en mi investigación "El poder y el amor. Su interrelación en la obra de Epicteto" (2016), realizada en la Universidad Nacional Autónoma de México. those vicious actions have a justification in a superior Cosmological level because they are pre-determined and ordered by the God-Providence. This leads us to the possibility of observing that the stoic philosophy of history, particularly the epictetean, is analogous to some modern speculative systems of history like the ones developed by Vico or Hegel.

\section{Introducción ${ }^{1}$}

Francois Chatelet en su La naissance de l'histoire, de 1962, habla de una "filosofía de la historia" de Platón en la cual se "reivindica la posibilidad de una liberación de la humanidad mediante el saber" (1985: 281), es decir, una interpretación de la historia en la que el telos de la humanidad es la sabiduría humana, un devenir histórico con un fin ético (uno análogo al que, según mostraremos, propugnan los estoicos). Chatelet también reconoce una "filosofía de la historia" desarrollada por los antiguos sofistas (1985:310-311), otra por Jenofonte (1985:387), otra más por Aristóteles (al reflexionar, dentro de la Poética, en lo que es en sí la disciplina de la historia y sus distinciones con la poesía está haciendo filosofía de la historia) (1985: 423), etc.

André Neher afirmó que la "filosofía de la historia", en su aspecto especulativo, se practicó desde la más remota Antigüedad, con seguridad desde los antiguos judíos. ${ }^{2}$ Se cultivaba como una "reflexión valorativa de los sucesos del pasado" (Larroyo y Escobar, 1971: 182). El especialista en la cultura griega, Werner Jaeger, por igual colocó el origen de la "filosofía de la historia" en la Antigüedad, aunque ya lo ubicó tardíamente, en el siglo II d.C., siendo obra de los cristianos (1965: 93) (por influencia judía más que griega). Aquí, análogamente, tomamos por irrefutable la existencia de una "filosofía de la historia" (entendida ampliamente como una interpretación filosófica del pasado humano -de su desarrollo, de los actos humanos históricos, de su telos, etc.-) en la obra del estoico del siglo I-II d.C., Epicteto. Pasemos a explicar en qué consiste la "filosofía de la historia" epicteteana y su vinculación con la philía y la guerra.

\section{La philía verdadera y la pasional y la utilización filosófica de los acontecimientos históricos}

En las Disertaciones, el ex-esclavo Epicteto expuso un pasaje histórico sobre las conquistas de Alejandro Magno con un propósito ético. En el capítulo de aquella obra titulado "Sobre la amistad", el filósofo enseña la forma de llegar a la felicidad (eudaimonía) estudiando lo que es la philía ${ }^{3}$ y simultáneamente nos la ejemplifica a través de la historia. El rememorar el pasaje histórico sobre Alejandro no tiene como objetivo llegar a la verdad histórica sino a la Verdad cosmológica-metafísica, la que de cualquier forma abarca a la primera. Veamos el pasaje al que nos referimos:

Pues, en general, no os engañéis, cualquier animal a nada se habitúa tanto como a su propia conveniencia. Y lo que le parece que le estorba-sea ello un hermano, un padre, un hijo, un amado o un amante- lo odia, lo rechaza, lo maldice. Pues,

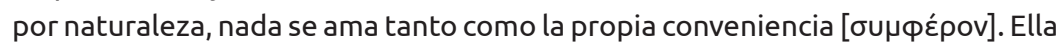
es padre y hermanos y parientes y patria y dios. Cuando nos parece que son los dioses los que ponen impedimentos, hasta a ellos los insultamos y derribamos sus estatuas y prendemos fuego a sus templos, como mandó Alejandro prender fuego a los templos de Asclepio cuando murió su amado (Diss. II.12.15-17). ${ }^{4}$

Observemos que Epicteto establece que: el colocar la "conveniencia" (tó sumphéron) personal en cuestiones incorrectas acaba con 1) nuestra posibilidad de ser felices, 
esto porque colocar erróneamente la conveniencia nos lleva a tener pasiones que 2) destruyen, a su vez, el estado de ánimo en el cual consiste la eudaimonía. Como la "conveniencia" es algo a lo que el ser humano se inclina por naturaleza, el humano siempre tratará de conseguirla, cueste lo que cueste.

El objetivo de Epicteto es responder a la pregunta ¿dónde debe poner cada persona su sumphéron (para ser feliz)?, ¿qué le conviene al ser humano? De acuerdo con Epicteto y con la antigua escuela estoica, cada persona debe poner su sumphéron precisamente en aquello y sólo en aquello que lleva al ser humano a la felicidad, es decir, en la virtud (arethé) (Laercio VII, 89). ${ }^{5}$ La virtud fue definida por los estoicos como el actuarconforme a los designios del Destino-Dios-Naturaleza (Lactancio, Instituciones divinas III 8/S.V.F I 179), ${ }^{6}$ siendo este actuar lo mejor que cualquier humano puede hacer para evitar la infelicidad.

Para la Stoa cada acontecimiento (incluyendo el histórico), cada suceder en todo el Cosmos, está regido y (pre)dispuesto por aquel Dios-Naturaleza. Hay que actuar como Dios desea pues ese Dios permea todo, es el Cosmos-Naturaleza mismo (Cfr. Brun, 1997: 71). Por ende, en el estoicismo, el hombre sabio-virtuoso es el que siempre acata lo que es conforme al Destino-Naturaleza (Cfr. Diss., II.10.5).

La actitud de Alejandro Magno ante la muerte de Hefestión relatada por Epicteto puede ser improbable históricamente. Podemos afirmar o, al menos intuir, que este pasaje es falso por la siguiente lógica: un buen conquistador siempre pone su sumphéron en las ventajas militares y políticas para la guerra que esté sosteniendo, su conveniencia se encuentra por encima de cuestiones como la philía. El pasaje histórico descrito por Epicteto puede ser inverosímil si consideramos que Alejandro fue "un buen conquistador", quizá el mejor de todos en la Historia, según se desprende de sus logros, ergo, no se sigue su actuar citado (Disertaciones II XXII). Si el líder hubiese actuado como Epicteto afirmó, estaríamos ante un hombre que parecería dominado por las pasiones, alguien que prestaba mayor atención a sus sentimientos que a dirigir correctamente la política y la guerra.

Dejando a un lado la "lógica" y las intuiciones, un "buen" historiador necesita, para refutar la versión de Epicteto, de otras fuentes sobre el pasaje. Y tenemos otra fuente antigua que contradice lo descrito por Epicteto, nos la da Arriano (el mismo que compiló las enseñanzas de Epicteto en las Disertaciones). Éste afirma que el haber mandado a destruir el templo de un dios es propio de un "bárbaro", asegura en cambio que el afecto de Alejandro Magno para con Hefestión es más congruente con la anécdota que recogen ciertos historiadores (no dice cuáles) de que el conquistador mandó ofrendas al dios de la medicina Asclepio y un mensaje que decía "Aunque el comportamiento de Asclepio no me ha sigo nada benévolo, al no salvar a mi amigo [...]".7 En este caso, ¿a qué versión creer? Para responder a lo anterior debemos de tener presente que el primordial y prácticamente único objetivo de Epicteto, al relatar el pasaje, no era indagar lo que realmente hizo Alejandro cuando murió Hefestión, sino que era ilustrar al estudiante de filosofía cuál era el comportamiento de alguien que no quiere ni 1) la posibilidad de ser feliz, ni 2) alejarse de la eudaimonía.

Podemos afirmar que Epicteto quiere establecer y poner en claro que Alejandro destruyó su felicidad o, mejor, su posibilidad de ser feliz al dejar de ser dueño de sí mismo (una característica infalible del individuo virtuoso) y comenzar a perpetrar actos iracundos y destructivos contra los dioses, y todo por colocar su conveniencia donde no debía, en la vida de alguien más. ${ }^{8}$ Para ejemplificar de forma elocuente, clara y familiar, al individuo pasional, nuestro filósofo necesita de un pasaje conocido de un hombre conspicuo del pasado. Así que utiliza una versión específica (¿y falsa?) del pasaje de la muerte de Hefestión, aquel donde el joven conquistador insulta deidades y destruye sus efigies. Es probable entonces que, para que su lección
5. Traducción de Antonio López Eire, en Los filósofos estoicos, p. 89.

6. Stoicorum Veterum Fragmenta. Traducción de Cappelleti, en Los estoicos antiguos, p. 117.

7. De hecho, Arriano dice también que Alejandro pidió a los dioses (en especial a Amón) que divinizaran a su amado. Véase por igual a Wirth (1986: 80 y 89).

8. Ricardo Salles (2012) ha analizado concienzudamente cuáles acciones son correctas y cuáles no para la persona que ama y tiene a su ser amado en peligro de muerte, según Epicteto. Estas acciones son juzgadas de acuerdo con el concepto de oikéiosis (el afecto de los seres sensibles hacia ellos mismos) y lo que es o no "natural", sin embargo, revisar estos puntos están más allá de los propósitos de nuestro estudio. 
9. Al respecto véase Brittain (1996: 332-354).

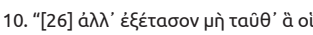

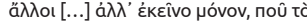

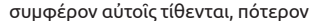

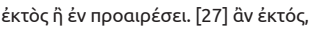

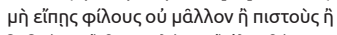

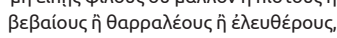

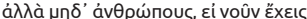
[...]" (Epicteto, Epicteti Dissertationes ab Arriano digestae,1916). impactara más en sus alumnos, recurriera a una anécdota sobre uno de los más famosos hombres de la historia, Alejandro Magno. Así, Epicteto explica que la razón del sufrimiento del conquistador radica en que éste colocó su sumphéron donde no debía, en concreto, en la philía incorrecta (por pasional) hacia Hefestión así como en la salud de éste, en vez de colocarla en la arethé, en el intentar ser virtuoso siempre. Epicteto muestra aquí también, no explícitamente, una idea sancionada por el estoicismo, que la philía verdadera no es pasional ni viciosa ("Epictetus provides a rationale. He says that we should not consider people as friends, nor even as human, unless they locate their personal interest in the character of their will" (Sorabji, 2000: 184); para nuestro filósofo solo los sabios profesan la auténtica philia). El amoramistad (philía) de Alejandro hacia Hefestión no era un amor-amistad verdadero, pues éste no provoca sufrimiento, además, sólo lo profesa un sabio-virtuoso, pues el sabio es el único que puede amar sin que peligre su propia virtud.

Epicteto alecciona que hasta el más grande conquistador de todos los tiempos, Alejandro, se equivocó al colocar su conveniencia en Hefestión, padecer por ello y realizar un acto vicioso, que era recriminar a los dioses. Alejandro no colocó su conveniencia en comportarse conforme a la Naturaleza, en comportarse virtuosamente. Por esta equivocación el guerrero no pudo cultivar una philía verdadera y se impidió ser feliz al entregarse a la ira, que es un vicio. Repetimos, Epicteto utiliza al más famoso guerrero histórico hasta entonces para probar un punto filosófico, en específico un punto de la metafísica y la ética de la Stoa; trata de enseñar que la única manera para ser feliz, incluso para alguien extremadamente poderoso como lo fue Alejandro Magno, es saber dónde colocar la conveniencia. El conquistador debió de poner su "conveniencia" en el Dios-Naturaleza para ser sabio, no en Hefestión, como tampoco debió ponerla en las tierras, las riquezas, la gloria o el éxito militar, en ninguno de estos $u$ otros ámbitos indiferentes para la felicidad de la vida humana.

Epicteto, para enseñar ética, sólo requiere de afirmar que "A" personaje histórico realizó "A-X" acto, sin importar si "A-X" es verdadero o falso, para poder juzgar e ilustrar sobre la cualidad moral tanto de "A" como de su acción "A-ar". Es decir, nuestro filósofo no requiere de la verdad histórica para emitir un juicio o enseñanza sobre la ética. El propósito de nuestro filósofo no es conocer si "A" realizó o "A-X" o "A-y" o "A-Z"; no es la meta de Epicteto saber si Alejandro en verdad maldijo a los dioses y destruyó sus templos cuando falleció Hefestión. Su objetivo es conocer cuál es la cualidad moral tanto de cualesquiera personajes "A", "B", "C", y averiguar y explicar si sus distintos actos han sido moralmente correctos o no. Para lo anterior el filósofo violenta la verdad de la historia, incluso tal vez crea una nueva versión de los hechos realizando así una "filosofía [moral] de la historia". El juzgar y/o analizar filosófica y éticamente a cualquier personaje histórico y a sus acciones es una actividad muy cultivada de la "filosofía de la historia" (¿de qué está repleta la Filosofía de la historia de Friedrich Hegel si no es de juicios morales (Cfr. Hegel, 1956) de -los actos de- distintas personalidades, naciones y pasajes de la historia?).

La enseñanza que quiere impartir Epicteto es que el ser humano debe saber no colocar la "conveniencia" de uno mismo en nada exterior a uno mismo (nada fuera de nuestra capacidad de decidir o proháiresis, que es lo que nos permite colocar en un lado o en otro a nuestra conveniencia), ${ }^{9}$ como serían las riquezas, los amantes, la vida, la salud, el poder político y militar, y un largo etcétera (cosas cuya existencia o posesión no depende de uno), sino solamente colocarla en Dios-Providencia-Naturaleza y en la capacidad de decisión. Lo anterior lo vemos en el mismo capítulo de "Sobre la amistad":

Pero no examines lo que los otros [...] sino sólo esto: en dónde ponen su

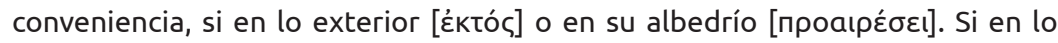
exterior [źktóc], no los llames amigos, y menos fieles, firmes o valerosos o libres, sino ni siquiera hombres, si eres sensato. [...] (Diss. II.22.26-27). ${ }^{10}$ 
La utilización de la historia con el fin de moralizar o enseñar filosofía (que en el estoicismo son una misma cosa, ya que al aprender filosofía te moralizas, mejoras) es un diáfano ejemplo de que, con el estoicismo, estamos ante una escuela filosófica plenamente pragmática. La utilización práctica, por parte de los estoicos, de todas las disciplinas: lógica, retórica, didáctica, etc., y no sólo de la historia, se debe a que aquellos filósofos creían que sólo el sabio puede hacer que la sociedad realmente funcione y se conserve (Cfr. Boeri y Salles, 2014: 751) (a través de todo el devenir histórico y hasta el final de los tiempos o Conflagración universal -la ekpírosis-, como le llamaba el estoicismo) (Cfr. Plutarco, Comm. not., 1066a (1075a-c), S.V.F. I 536) , ${ }^{11}$ por esto había que enseñar cómo ser un sabio-virtuoso.

La Stoa quiso dejar enseñanzas para la vida cotidiana, que aplicasen tanto para alcanzar al ideal del sabio-virtuoso o, al menos, para acercarse a él. Epicteto igualmente deseaba hacer entender que el único individuo libre es el que es sabio-virtuoso, y lo mostró al exhibir a uno de los más grandes griegos -Alejandro- como esclavo de sus vicios, y con ello, lo mostró como un no-sabio infeliz pese a todos sus logros políticos. (El decir que el no sabio o ignorante es infeliz es un argumento tradicional del estoicismo previo a Epicteto) (Cfr. Dragona-Monachou, 2002: 112-139). Epicteto reprende el comportamiento de los no-sabios que colocan su sumphéron en algo ajeno de Dios como en el amor excesivo o, mejor dicho, en la philía excesiva que es en realidad falsa. Tal sentimiento de philía incorrecta profesado por Alejandro hacia Hefestión es denominada por los estoicos como una pasión (pathé), es decir, un sentimiento incorrecto que lleva al vicio y a la infelicidad. Un sentimiento incorrecto del cual era esclavo, a decir de Epicteto, Alejandro Magno.

\section{La explicación moral de la guerra (pólemos) antigua}

Queremos ahora dar otros ejemplos de la reflexión sobre la historia por parte de Epicteto, que lo llevaron a construir una filosofía especulativa de la historia (aquella que tiene por objetivo "escribir una exposición del curso detallado de los acontecimientos históricos de tal suerte que quedaran de manifiesto su 'verdadero' sentido y su 'esencial' racionalidad" (Walsh, 1978: 24), (así como es una filosofía de la reflexión sobre pasajes históricos), al exponer cómo es imposibilitada la eudaimonía humana a lo largo de todo el devenir histórico -grecolatino- por causa de las pasiones (pathéiai), las cuales llevan a alejarse de la arethé. En específico Epicteto se centra sucintamente en el análisis de las pasiones que provocaron las guerras a lo largo de la historia.

En las Disertaciones muestra que la felicidad de los pueblos es impedida debido a que, de forma continua y común, la armonía o la philía entre individuos se destruye porque los integrantes de los diversos pueblos del mundo colocan su conveniencia fuera de ellos mismos, fuera de lo único que en verdad está en nuestro poder, el ser virtuoso a través de nuestra capacidad de decisión. Esta colocación de la conveniencia fuera de lo que está en nuestras manos (el decidir actuar de tal forma u otra), puede provocar las pasiones. Epicteto encuentra la causa de varias guerras concretas de la Antigüedad en el siguiente argumento: los integrantes de los pueblos que han estado en guerra colocaron sus "conveniencias" en otra parte que no era la capacidad de asentimiento personal o proháiresis y en lograr su buen uso, llevándolos a actuar pasionalmente.

Antes de continuar con los ejemplos históricos dados por Epicteto revisemos un poco más la epistemología estoica. El ser humano recibe en su alma impresiones o representaciones (phantasíai) del mundo exterior a través de sus sentidos (Cfr. Laercio VII 45-47) $)^{12}$ y, para el estoicismo, tanto los conceptos como las ideas también son tipos de representaciones (Cfr. Estobeo, Églogas I p. 236, 21). ${ }^{13}$ Esas impresiones pueden ser verdaderas o falsas y el ser humano tiene la capacidad de asentir (tomar como
11. En la traducción de Capelleti: Los estoicos antiguos, p. 287. Todo va a perecer en esa conflagración final, excepto Dios-Zeus.
12. En la traducción de Antonio López Eire: Los filósofos estoicos, pp. 124-127.

13. En la traducción de Capelleti: Los estoicos antiguos, pp. 59-60. 
14. En la traducción de Paloma Ortíz García: Disertaciones por Arriano, p. 139.
15. En la traducción de Paloma Ortíz García: Disertaciones por Arriano, pp. 242-243. [19] "ǒnou yàp âv tò 'ह́үü' kaì

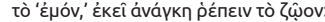

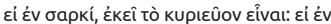

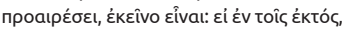

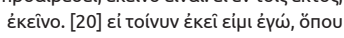

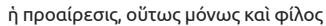

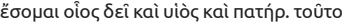

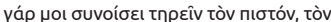

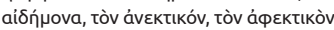

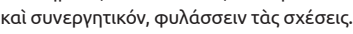

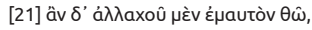

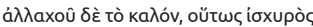
vívetal ò 'Eпıкоúpou $\lambda$ óvoc, ánофaívwv

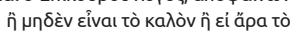

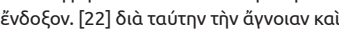

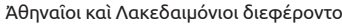

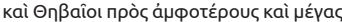

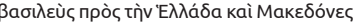

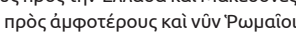

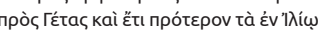

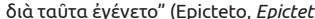
Dissertationes ab Arriano digestae, 1916). verdaderas) o rechazar (tomar como falsas) esas impresiones. Por lo anterior, el humano puede equivocarse epistemológicamente al asentir a falsas impresiones y rechazar impresiones verdaderas. Además, según Epicteto, el humano está siempre (pre)dispuesto a asentir a cualquier cosa (cualquier impresión) que le parezca verdadera (Cfr. Diss., I.28.1 $)^{14}$ (sin antes en verdad analizarla). A la capacidad de asentir o no asentir, específicamente, a las diferentes phantasiai, la Stoa la llamó proháiresis (Cfr. Long, 1996: 277). (El concepto epistemológico de proháiresis proviene, según Anthony Long, del presupuesto de que el plan de Dios-Naturaleza dispuso que los seres con alma tuvieran el dispositivo para discernir cómo vivir conforme a la Naturaleza (Cfr. Long y Sedley, 1987: 250), para asentir a las que son verdaderamente impresiones falsas y rechazar a las que son falsas).

Esto último implica una idea básica del estoicismo: que el plan del Dios-DestinoNaturaleza consiste en que los seres racionales puedan vivir conforme a sus designios (del mismo Dios), es decir, conforme a la misma Naturaleza (que es en lo que consiste ser-virtuoso). Los humanos tienen tal posibilidad de vivir conforme a la NaturalezaDios precisamente porque ésta les dio su capacidad racional. Los seres humanos tenemos por naturaleza el dispositivo para distinguir entre lo verdadero y lo falso (Cfr. Salles, 2014: 179-181).

Volvamos a la pólemos, ésta es causada entonces cuando los líderes militares y políticos, y sus seguidores, colocan su sumphéron en objetos exteriores como las tierras, las riquezas, la política, etc., rompiendo así la philia o armonía que debe de haber entre los pueblos:

En donde uno ponga el "yo" y "lo mío" a ello es fuerza que se incline el ser vivo. Si en la carne, allí estará lo dominante; si en el albedrío, allí estará; si en lo exterior, allí. Por tanto, si yo estoy allí donde mi albedrío, sólo así seré amigo, hijo y padre como se debe. Porque me convendrá esto: observar la fidelidad, el respeto, la paciencia, la abstinencia, la colaboración, mantener las relaciones [...]

Por ese desconocimiento [sobre dónde se debe de colocar la conveniencia] tuvieron diferencias [a] los atenienses con los lacedemonios, y [b] los tebanos con ambos, y [c] el Gran Rey con Grecia, y [d] los macedonios con ambos, y [e] hoy en día los romanos con los getas. Y [F] aún pasó lo de Troya (Diss. II.22.1923). ${ }^{15}$

En efecto, históricamente ciertas "diferencias" entre los distintos pueblos mencionados provocaron guerras reales. Epicteto conoce la historia y hace uso de ese conocimiento para ejemplificar a sus estudiantes, de una forma más familiar al citar pasajes históricos (como lo hizo con Alejandro), cuál es el propósito (y cuál no) del ser humano y cómo evitar 2) alejarse de la eudaimonía.

\section{El origen pasional de las guerras históricas.}

Las guerras que surgieron por colocar la conveniencia equivocadamente, según Epicteto, son las siguientes:

a) La "diferencia" (tó diaphéron) que enfrentó a atenienses y lacedemonios provocó la Guerra del Peloponeso (431-404 a.C.) y luego la Guerra de Corinto (395-387 a.C.).

b) La "diferencia" habida entre tebanos contra atenienses y espartanos llevó a la conocida como Guerra de Beocia o guerras contra la "hegemonía tebana" (hacia 373346 a.C., o al menos tal guerra es la que creemos se refiere). 
c) La "diferencia" habida entre el "Gran rey" de Persia -Darío I y luego su hijo Jerjes I- contra los griegos en general provocó las Guerras Médicas (499-449 a.C.), cronológicamente anteriores a las dos primeras mencionadas en el texto pero que Epicteto menciona después.

d) La "diferencia" entre los macedonios es la que causó el expansionismo de los reyes de Pella quienes primero se lanzaron en guerra contra Grecia y luego, con Alejandro Magno contra Persia y aún más allá (desde 358 a.C. hasta 323 a.C.).

e) La "diferencia" entre romanos y getas se trata con seguridad del conflicto que el Imperio Romano tuvo con la tribu dacia de los getas (una entre muchas tribus dacias con las que guerrearon los romanos), alrededor del río Danubio (85-88 d.C.) y llamada por algunos historiadores Guerras Dacias. Perteneciente a la serie de contiendas encabezadas por el emperador Domiciano, ya en tiempos de Epicteto.

f) La "diferencia” que causó la Guerra de Troya lanzó a aqueos contra troyanos, griegos contra griegos (esta guerra es cronológicamente anterior a las demás).

Veamos cuáles eran las "diferencias" que pudieron provocar las distintas guerras que menciona Epicteto. Éste explica a) el origen de las guerras del Peloponeso y de Corinto en razón de que tanto atenienses como espartanos pusieron equivocadamente su sumphéron en cosas exteriores, las cuales Epicteto no menciona explícitamente. Esas cosas exteriores que provocaron las guerras del punto a) podrían ser para Epicteto la que nos dicen las fuentes históricas, ${ }^{16}$ que Atenas y Esparta deseaban: o Ia) el incrementar su gloria-prestigio y/o IIa) el mejorar su economía y/o IIIa) el aumentar el número de polis adscritas a sus respectivas Ligas y/o IVa) el aumentar su poder político y/u otros motivos. Epicteto consideraría a esos cuatro objetivos de las polis (como cualesquiera otros objetivos que no sean el ser-virtuoso) como cosas indiferentes para la verdadera felicidad, esas cuatro cuestiones, si se hubieran conseguido, no hubiesen traído la eudaimonía a los miembros de las polis de Atenas o Esparta. Si ninguna de las dos polis hubiera colocado su sumphéron en ninguna de esas cuatro cuestiones se hubiera evitado, a decir de Epicteto, la Guerra del Peloponeso. Si cada uno de los dirigentes e integrantes de las polis hubiesen conocido la filosofía, hubiesen colocado sus "conveniencias" en lo que depende de uno y así evitado el pólemos. Pero como no fue así, Atenas y Esparta cayeron en el vicio, las pasiones y la infelicidad. Atenas y Esparta fueron esclavas de los indiferentes como la gloria, el poder económico, el poder “imperial” y político.

Algo idéntico a lo dicho sobre a) las guerras del Peloponeso y de Corinto puede decirse de b) la Guerra de Beocia y de c) las Guerras Médicas: tanto los líderes como cada uno de los integrantes de las polis o imperios que participaron en estas guerras hicieron mal uso de su capacidad racional y colocaron sus "conveniencias" donde no debían.

En cuanto a la cuestión d) del origen las guerras de expansión macedonias digamos un poco más. Las guerras de expansión política y bélica de Macedonia fueron iniciadas por Filipo II hacia el 358 a.C. Según expone Marco Tulio Cicerón en Sobre la República, la guerra de Macedonia contra Persia se originó porque los macedonios deseaban vengar la destrucción de templos griegos hecha por el rey persa Jerjes y su ejército durante las Guerras Médicas ("hanc bellandi causam inferebat, quod vellet Graeciae fana poenire; quae ne reficienda quide Graii putaverunt, ut esset posteris ante os documentum Persarum sceleris sempiternum" (Cicerón, De re publica III.15), ${ }^{17}$ se originó pues en un suceso más de cien años anterior a cuando los macedonios se lanzaron contra los persas (358 a.C.). En esta explicación del deseo de atacar Persia no parece haber una equivocación epistemológica-moral (colocar en algo equivocado la conveniencia) en la decisión de los macedonios. Pues, Cicerón da una cierta
16. Tucídides se inclina más a que la causa de la guerra fue la ambición ateniense que amenazó a Esparta. Véase Tucídides, Historia de la Guerra del Peloponeso I.23.6.

7. En la edición de C. F. W. Mueller, 1889: 85. 
18. Entendiendo que aquí "acontecimiento histórico" aplica a cualquier suceso en el devenir del mundo y no sólo a aquellos que sean considerados "importantes", "trascendentes", "decisivos", etc., por y para la humanidad, ya que todo es importante en el "panteísmo" estoicismo pues Dios está o permea en todo (acontecimiento).

19. En la traducción de Paloma Ortíz García: Disertaciones por Arriano, pp. 239-245.

20. En la traducción de Antonio López Eire: Los filósofos estoicos, p. 195.

21. Yendo aún más lejos, John Sellars (2007: 15) nos hace observar que Epicteto y Marco Aurelio (como alguna vez Diógenes el Perro) afirmaron que sólo los sabios eran en verdad hombres; esto, considero, nos llevaría a la congruente conclusión de que, porque los no-sabios no son hombres, no pueden cultivar la (verdadera) philia (ergo, existen las guerras y contiendas). “justificación" para la guerra al decir que los macedonios comenzaron su expansión militar teniendo en mente un buen propósito, a saber, un propósito virtuoso que obedece al deber civil, social y/o religioso: vengar los insultos a los dioses nacionales. Sin embargo Epicteto utiliza de nuevo una versión de un pasaje de la historia, opuesto al descrito por Cicerón, uno en que los hechos son llevados a cabo impulsados por una pasión. Para Epicteto las guerras macedónicas fueron llevadas a cabo por motivos egoístas y no por motivos honorables (también es originada por una diferencia con los griegos y con los persas, a decir de nuestro filósofo), esta versión le sirve mejor para explicar filosóficamente las causas de esas mismas guerras históricas. De nuevo estamos ante una explicación filosófica moral que expone a la historia como repleta de pasiones y vicios por sobre una explicación de índole más optimista.

La interpretación epicteteana de los actos históricos implica una verdadera "filosofía de la historia" pues se trata de una interpretación omniabarcante de la Historia y que no explica sólo a un acontecimiento (aislado) de la historia, es una explicación que puede aplicarse a todos los acontecimientos históricos, ${ }^{18}$ de cualquier época, que resulten en un sufrimiento, en la "infelicidad" para el ser humano (es decir, en prácticamente todos los acontecimientos históricos).

Lo que Epicteto quiere también poner en claro a sus estudiantes es que el mundo entero está poblado de ignorantes o no-sabios; pues, la causa de que haya tantas guerras y tantos conflictos en la historia radica en que el mundo está lleno de nosabios, de personas que son esclavas de los bienes externos que no llevan a la eudaimonía, de aquellos que desconocen cómo actuar conforme a lo designado por el Destino día a día. Podemos ir más lejos: no importa la versión histórica de un hecho que haya causado "daño", "desgracias", "dolor", Epicteto aún podría adjudicar el origen de ese hecho a la ignorancia humana, que implica la carencia de libertad, valentía y firmeza en los actos humanos (Cfr. Diss. II.22). ${ }^{19}$ Por eso es que el fundador del estoicismo Zenón de Citio, dijo, como Epicteto, que la philía verdadera no existe mas que en los sabios (Cfr. Laercio, VII 124), ${ }^{20}$ pues si existiera entre los no-sabios no surgiría en lo absoluta ninguna pólemos o contienda humana. ${ }^{21}$

En lo referente a e) las Guerras Dacias, encontramos una de las pocas críticas que hizo Epicteto contra la política del Imperio Romano, la potencia mundial en su tiempo. El filósofo afirma implícitamente, al mencionar esa particular guerra, que los romanos también son no-sabios y que se equivocaron al colocar su sumphéron en algo inapropiado y, al hacerlo, se originó, como seguramente aconteció muchas veces antes, ese concreto pólemos. Esta es una de las pocas "observaciones" que hizo contra los romanos; el filósofo es indulgente, a lo largo de todas sus enseñanzas, para con las acciones bélicas y conquistadoras de los romanos: hasta donde sé, no menciona ni comenta otros casos bélicos romanos a lo largo de todas las Disertaciones ni en el Enchiridion (aunque esto quizá también sea por tradición filohelénica, derivada del sólo hecho de ser griego y querer utilizar ejemplos de la historia bélica griega, más que de la romana) ni tampoco, sorpresivamente, analiza los famosos actos inicuos de los gobernantes de la historia de Roma conocidos por su perversidad como Sila, Tiberio, Calígula o Nerón.

Puede decirse que la "filosofía de la historia" de Epicteto, por omisión, se pone del lado de los vencedores de la historia de su época. Así, su sistema puede contener lo que, valga el anacronismo, ciertos representantes de la Teoría Crítica han atacado de la filosofía de la historia moderna: su "toma de partido [...] [que la hace] cómplice de los vencedores [por omisión en el caso de Epicteto], lo cual impide ver bien a las víctimas de los conflictos del pasado [no nos permitiría ver la visión de los derrotados por los romanos: cartagineses, egipcios, galos, celtas, britanos, germanos, dacios, etc.]" (Rohbeck, 2007: 63-79). Es probable que Epicteto, de forma no deliberada, se ponga "del lado" de los 
romanos en el sentido que poco conoce o casi nada critica de los hechos y acciones de los romanos contra los pueblos de Oriente o los bárbaros del norte. Su crítica contra las decisiones (morales) de individuos del pasado, por estar pensada para ilustrar a los romanos, y, tal vez, para no herir sus susceptibilidades, tiene como ejemplos figuras famosas de la historia griega (y persa) y no toma ninguna figura de la historia de Roma: Paris Alejandro, Helena, Héctor, Darío I (el Gran Rey), Jerjes (el Gran Rey), Temístocles, Epaminondas, Filipo II, Alejandro Magno, entre otras, todas ellas griegas.

No obstante, la postura epicteteana se matiza en su toma de posición al lado de los vencedores de la historia porque sí hace alusión de que todos los seres humanos sufren: tanto victoriosos como derrotados en las guerras han comenzado sus conflictos por errores epistemológicos que los han llevado igualmente a la infelicidad o los han dejado ahí. Aquel asegura que si todos los pueblos o culturas, no importa si son los poseedores del poder o los sojuzgados, tanto sus líderes como sus seguidores (patricios o plebeyos, amos o esclavos), hubieran colocado sus "beneficios" en su

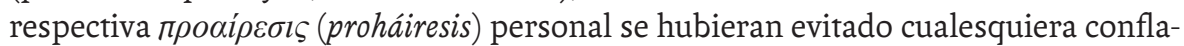
graciones bélicas y sus devastaciones (que afectan a todos los estratos por igual). En efecto, lo anterior implica que, si todos los individuos, a lo largo de toda la historia, colocaran su "beneficio" o "interés" en Dios y en la proháiresis no existirían guerras ni sus consecuentes desgracias. Esto es, si el ser humano hiciera uso correcto de su racionalidad ya no habría más infelicidad, siendo ésta eliminación de la infelicidad el fin último de (esta filosofía de la historia de) el ser humano. Análogo final, aunque lo llamen de otra forma, tienen otras filosofías modernas de la historia: la ilustrada, la positivista, el materialismo histórico, todas ellas tienen como meta final para la historia la mejora humana, esto es, de cierta forma, su ulterior felicidad lograda a través del progreso material o una forma específica de gobierno y economía.

Pasemos a revisar al origen de f) la Guerra de Troya. "Y aún antes por eso pasó lo de Troya. Alejandro era huésped de Menelao, y si alguien hubiera visto su mutua cordialidad no habría creído a quien le dijera que aquéllos no eran amigos. Pero alguien echó en medio un bocado, una hermosa mujercita [Helena]; y, por ella, la guerra.", afirma Epicteto (Diss. II.22.23-24). ${ }^{22}$ En cuanto a este pólemos, nuestro filósofo sí habla explícitamente sobre el origen concreto e histórico ${ }^{23}$-o al menos lo que dicen las fuentes literarias- de la Guerra de Troya (a diferencia de lo que hace con la Guerra del Peloponeso, la Beocia o la Dacia, de las cuales no explica su origen circunstancial histórico concreto). Como en el caso de Alejandro Magno, quizá Epicteto se extiende en la Guerra de Troya por ser tradicionalmente un tema más conocido o más atractivo para griegos y romanos que las otras guerras mencionadas, teniendo así más impacto su discurso.

Para probar su punto, Epicteto cambia la creencia tradicional de los griegos sobre Helena (sancionada en la Ilíada): ella no es la verdadera causante de la contienda entre aqueos y teucros sino que los agentes causantes son el enamorado y raptor Paris Alejandro y el esposo de Helena, Menelao, igualmente enamorado. Los dos guerreros colocaron su sumphéron en Helena así como en sus propias reputaciones. Y ya que las personas quieren a su "conveniencia" por sobre todas las cosas, luego, Alejandro y Menelao querían a Helena y/o a sus reputaciones sobre todas las cosas. Luego, el hecho de que ambos tuvieran en Helena su "conveniencia" causó finalmente la Guerra de Troya. Si no hubiera sido por esa equivocación de colocar la "conveniencia" en una mujer, se hubiera evitado la contienda. Así, Epicteto rechaza a la tradicional visión de Helena como causa de discordias, colocando la culpa en Menelao y Paris Alejandro. Ambos personajes se convirtieron en esclavos de una cuestión exterior a ellos (y por esto mismo, fuera de su dominio), ${ }^{24}$ fueron esclavos de Helena; alguien cuya posesión estaba fuera de su poder. Se trató de una equivocación epistemológica porque los dos griegos asintieron a una falsa impresión: creer que Helena era un Bien para ellos.
22. En la traducción de Paloma Ortíz García: Disertaciones por Arriano, p. 243. 23. Sabemos que la Guerra de Troya sucedió históricamente pero aún desconocemos con certeza la época y el nombre de los participantes reales con certeza, Epicteto también, por lo que él está reinterpretando lo que la literatura (Homero) dice de aquel suceso histórico.

24. Recuérdese que lo único en nuestro dominio para el estoicismo es nuestra proháiresis o capacidad de decidir y de asentir o no. 
5. La virtud es lo único necesario para vivir bien o feliz, decía Zenón. "Quia, cum a Zenone, inquam, hoc magnifice tamquam ex oraculo editur: 'Virtus ad beate vivendum se ipsa contenta est'

[...]" (Cic. de Finibus Bonorum et Malorum

V.79/S.V.F. I.187). En la edición de 1915: Tulli Ciceronis scripta quae manserunt omnia, p. 195. En la traducción de Capelleti: Los estoicos antiguos, p. 120
Los estoicos trataron de enseñar que siempre se debe intentar el asentimiento a las verdaderas impresiones y el rechazo de las falsas. Siendo las ideas verdaderas impresiones verdaderas que concuerdan con los designios del Dios-Naturaleza. Paris y Menelao recibieron y asintieron a la idea-impresión de que Helena es un Bien, una falsa impresión pues Helena no es un Bien ya que el único Bien es la arethé. Helena es un indiferente porque no es una cuestión o cosa lleve al único Bien en el Cosmos, ${ }^{25}$ la virtud: "Virtus ad beate vivendum se ipsa contenta est". Estamos de nuevo ante una explicación del origen de las guerras que surge de una filosofía de la historia en la que se explica, de manera completísima, cada acto humano por medio de una teoría del conocimiento que interconecta sólidamente la psicología, la ética, la física y la metafísica.

Epicteto, al citar ejemplos de la historia bélica, nos muestra cómo es impedida la felicidad en los integrantes de todos los pueblos del mundo. La causa de varias guerras concretas de la Antigüedad Grecorromana se encuentra, entonces, en que los individuos de las distintas entidades políticas asintieron a falsas ideas-impresiones. A decir del filósofo estoico las siguientes explicaciones filosóficas de la historia son acertadas: los atenienses, así como los tebanos, asintieron a la falsa idea de que ser la potencia principal entre las polis griegas era un Bien; Darío I y Jerjes asintieron a la falsa idea de que conquistar Grecia era un Bien; Alejandro Magno asintió a la falsa idea de que Hefestión o conquistar el mundo entero eran un Bien; los romanos asintieron a la falsa idea de que dominar y expoliar a todos los bárbaros era un Bien. No importa cuál fue la falsa idea a la que los distintos personajes asintieron, el punto es que ninguno colocó su proháiresis donde debía, si lo hubieran hecho, no hubieran provocado ninguna guerra.

Epicteto, al tomar pasajes históricos como los de Alejandro Magno o los de las guerras de la Antigüedad no sólo hace filosofía moral o filosofía política sino que hace indudablemente filosofía de la historia si entendemos que ésta

no construye originalmente la historia, pero la tiene ante sí, hecha del todo, pensada y relatada y provista de todos los títulos y sumarios a que se acoge y merced a los cuales, sutilizándolos, o, por mejor decir, retorciéndolos, se las da de ofrecer la que llama historia interior (Croce, 1971: 132).

Epicteto sutiliza y, quizá, retuerce el pasado y otorga una historia interior entendida como herramienta para conseguir la libertad interior humana, tal y como la concibió Croce. En las ejemplificaciones del filósofo tenemos ante nosotros una diáfana muestra de referencia al pasado con el propósito de moralizar a los líderes del mundo o, más específicamente, a los futuros gobernantes del Imperio Romano (Cfr. Sandbach, 1975: 147). Los hijos de la cúpula gobernante romana asistían a sus clases, como asistían a las de muchos otros eruditos y filósofos griegos desde hacía ya siglos previos a su época. Los estoicos querían dejar enseñanzas para la vida cotidiana de cualquier no sabio, y, en especial, querían dejar enseñanzas a los no-sabios gobernantes de su momento o a los que próximamente iban a serlo, pues estaban conscientes que los gobernantes influían mucho más sobre la sociedad en general que, digamos, los estratos bajos.

La solución de Epicteto para no caer en los errores morales-epistemológicos del pasado, bien ilustrados a través de la historia de los conflictos bélicos, se encuentra en la filosofía. Su solución era una simultáneamente epistemológica, psicológica, ontológica tanto como ética. "Pero no examines lo que los otros [...] sino sólo esto: en dónde ponen su conveniencia [...]" (Diss. II.22.23-24). ${ }^{26}$ Es a través del buen uso de la proháiresis que se podrá asentir siempre a la idea-impresión de que la virtud es el único Bien. Para que, al asentir a tal impresión y actuar conforme a ella se cumpla con el telos humano, es decir, se cumpla con el fin de la Humanidad o fin de la
26. En la traducción de Paloma Ortiz García: Disertaciones por Arriano, p. 243. 
Historia humana el cual es impuesto por Dios, que el ser humano actúa conforme a la Naturaleza.

\section{La "filosofía de la historia" epicteteana, conclusiones.}

Epicteto reflexiona en torno a la historia y analiza ciertos pasajes de la misma con un propósito didáctico. Y su forma de interpretar la historia muestra semejanzas con las filosofías de la historia modernas. Cabe pues enumerar y comentar los paralelismos entre las definiciones, descripciones u objetivos de algunas de las "filosofías especulativas de la historia" modernas y el sistema filosófico de Epicteto (a partir de los pasajes revisados).

El sistema estoico epicteteano:

1) Concibe cada uno de los acontecimientos del cosmos y del hombre (los hechos históricos) están regidos por la Providencia-Dios. Esto es análogo a la filosofía de la historia de Vico $^{27}$ y a la de Hegel. ${ }^{28}$ Es decir, el sistema de Epicteto es una filosofía de la historia en el sentido de las llamadas filosofías de la historia "sustanciales" o "especulativas" (Day, 2008: XII). Se trata de una "filosofía de la historia" existente desde la Antigüedad, la cual ha especulado sobre la Providencia, el destino o el determinismo (Lemon, 2003: 14-18).

2) Considera que todas las actividades (históricas) del ser humano tienen un propósito (final) 0 telos, el cual consiste en que el ser humano actúe conforme a los designios de Dios-Naturaleza. Recuérdese que muchas de las grandes filosofías de la historia modernas, como el materialismo histórico o el positivismo, le dan un telos cuasitrascendente, o plenamente trascendente, a la historia. Ese propósito final de los acontecimientos es, según una definición de filosofía de la historia de Von Mises, "una meta específica diferente de las metas que los hombres en acción tratan de alcanzar" (1975: 146). Y, de acuerdo al estoicismo, la meta de Dios y la de los hombres difieren cuando estos últimos son no-sabios. Estamos ante una filosofía de la historia en la que "Hay un significado en la secuencia de acontecimientos que está por encima de las intenciones de los hombres" (1975: 146).

3) Interpreta al pasado humano no en busca de la verdad sino con un propósito ético-filosófico, tal propósito consiste en que el ser humano siempre progrese moralmente. Lo anterior es similar a los propósitos morales de las "filosofías de la historia" como el materialismo histórico; en este sistema pragmático se intenta que la humanidad progrese hasta un estadio superior de igualdad y bienestar; similar objetivo tiene la humanidad en conjunto para historiadores (-neo-marxistas) como Eric Hobsbawm, quien dice que el ser humano siempre debe progresar moralmente, cumplir con el proyecto ilustrado (Cfr. Ortiz, 2014, 237).

4) Manipula el pasado humano con el propósito didáctico y filosófico de que el ser humano cumpla con el telos del cosmos (cumplir con el punto I). Tal y como Hegel manipuló la historia para "demostrar" su filosofía (Ramírez, 2011, 141).

5) Su epistemología es una bien acabada explicación (gnoseológica, psicológica y moral) de cada uno de los actos del ser humano a través de la historia. En este sentido también estamos ante una "filosofía de la historia" porque, de acuerdo a Aviezer Tucker, ésta es una sub-área de la metafísica que intenta discernir los últimos constituyentes de todo, como lo hace la filosofía de la naturaleza (Cfr. Tucker, 2009: 4), y, según estimamos, la epistemología estoica es de este tipo de filosofía de la naturaleza que trata de discernir la verdad última.
27. Dice Giambattista Vico (2006: 95) que el orden actual de las cosas y la historia de todas las naciones fue "impuesto por la Providencia". 28. Dice Hegel (1956: 36): "God governs the world; the actual working of his government -the carrying out of his plan- is the History of the World". 
6) Su epistemología otorga sentido a la ética y a la metafísica, lo cual implica dar un sentido transhistórico y trascendental (ético y metafísico) a la historia humana (como lo hacen muchas de las grandes filosofías de la historia). En otras palabras, la epistemología del estoicismo epicteteano descubre indirectamente lo que quiere descubrir la "filosofía de la historia" en su definición más "tradicional", es decir, descubrir "el curso real de los acontecimientos históricos" (Walsh, 1978: 10).

7) Concibe a la filosofía como la mejor manera de comprender el sentido de la (historia de la humanidad) porque nos hace comprender (la mecánica de) los actos humanos; y concibe a la historia como una excelente manera de ejemplificar su sistema filosófico. Es decir, es una "filosofía de la historia" como la que Jacques Maritain acertadamente dice que Agustín de Hipona desarrolló, donde la filosofía de la historia "attempts to bring out the inteligible [...] meaning of the sequence or development of events in time". ${ }^{29} \mathrm{Y}$ tal significado (metafísico) del desarrollo de los eventos del tiempo sólo puede discernirse, de acuerdo con Epicteto, a través del estudio de la filosofía y de sus tres ramas: la física, la ética y la lógica (la clásica división tripartita estoica, donde el estudio de cada una de esas tres ramas llevará al ser humano a saber cómo ser-sabio-virtuoso obedeciendo a la Naturaleza) (Cfr. Tucker, 2009:4). Conocer ese curso real de los eventos en el tiempo (histórico y cosmológico), y de su significado, sólo se logrará, pues, mediante la aplicación de las tres disciplinas filosóficas tanto al estudio de la historia como al de los demás ámbitos humanos: política, retórica, arte, religión, medicina-salud, etc.

El carácter práctico de la filosofía de Epicteto, debido quizá a la época turbulenta y peligrosa para los filósofos que le tocó vivir a finales del siglo I d.C. y principios del siglo II, no debe de ser pasado por alto. Seguramente sus discursos tenían la intención de ayudar a superar las injusticias y tiranías de los gobernantes de su época, darle una justificación filosófica y ética a cada uno de los acontecimientos humanos por más injustos que parezcan. También podía haber tenido la intención de darle sentido al devenir histórico que los nihilistas y escépticos en general han considerado como vacío de un verdadero significado.

Sobre las deliberaciones de Epicteto en torno a la libertad que gozan los que viven de acuerdo con el Dios-Naturaleza, Susanne Bobzien dice lo siguiente: "[...] the motivation [de Epicteto] is chiefly prudential and pragmatic: if one is aware of the limits of one's power, one's future plans will be more realistic [...] and consequently ones future disappointments will be minimized" (Bobzien, 1998). Su "filosofía de la historia" es pues pragmática (tal y como lo es la de los -auténticos- marxistas). Nunca podremos negar que para Epicteto la filosofía práctica y la ética se pueden comprender y ejemplificar con el pasado humano (tal y como pensaban Kant, Marx, Comte, etc.), y, por esto, su análisis completa y plenamente filosófico del pasado no es sino también un tipo de "filosofía de la reflexión sobre la historia". 


\section{Bibliografía}

»Arriano (1982). Anábasis (trad. Guzmán Guerra, A.). Madrid: Editorial Gredos.

» Boeri, M. D. \& Salles, R. (2014). Los Filosófos Estoicos. Ontología, Lógica, Física y Ética. Traducción, Comentario Filosófico y Edición Anotada de los Principales Textos Griegos y Latinos. Sank Agustin: Academie Verlag.

" Cappelleti, A. (trad. y ed.) (1996). Los estoicos antiguos. Madrid: Editorial Gredos.

" Cicero, M. T. (1915). de Finibus Bonorum et Malorum, en M. Tulli Ciceronis cripta quae manserunt omnia. Leipzig: Teubner. Recuperado de:http://www.perseus. tufts.edu/hopper/text?doc=Perseus\%3Atext\%3A2007.01.0036\%3Abook\%3D5\% 3Asection\%3D79.

» Cicero, M. T. (1889). De re publica. C. F. W. Mueller (Ed.). Leipzig: Teubner.

»Diógenes Laercio (1990). Los filósofos estoicos (trad. López Eire, A.). Barcelona: Promociones y Publicaciones Universitarias.

"Epicteto (2010). Disertaciones por Arriano (trad. Ortiz García, P.). Madrid: Editorial Gredos.

"Epicteto (1916). Epicteti Dissertationes ab Arriano digestae Libro II, XXII (26-27). Leipzig: B. G. Teubner.

»Long, A. A. \& Sedley, D. N. (1987). The Hellenistic Philosophers, Vol. I. Cambridge: Cambridge University Press.

» Tucídides (2008). Historia de la Guerra del Peloponeso. Madrid: Alianza Editorial.

\section{Bibliografía secundaria}

» Bobzien, S. (1998). Determinism and freedom in stoic philosophy. Nueva York: Clarendon Press.

" Brittain, C. (1996). The Compulsions of Stoic Assent. En Striker, G. (Comp.), Essays on Hellenistic Epistemologý and Ethics (pp. 332-354). Cambridge: University of Cambridge.

" Brun, J. (1997). El estoicismo (trad. Blanco Regueira, J.). Toluca: Universidad Autónoma del Estado de México.

"Chatelet, F. (1985). El nacimiento de la historia, La formación del pensamiento historiador en Grecia (trad. Suárez Bacelar, C.). Madrid: Siglo Veintiuno Editores.

"Croce, B. (1971). La historia como hazaña de libertad (trad. Díez-Canedo, E.). México: Fondo de Cultura Económica.

»Day, M. (2008). The Philosophy of History. An Introduction. Norfolk: Continuum.

"Dragona-Monachou, M. (2002). Epictetus on freedom/ Parallels between Epictetus and Wittgenstein. En Scaltsas, T. y Mason, A. (Eds.), The philosophy of Epictetus. Nueva York: Oxford University Press.

" Hegel, F. (1956). The Philosophy of History (trad. Sibree, J.). Nueva York: Dover Publications. 
» Jaeger, W. (1965). Cristianismo primitivo y paideia griega (trad. Frost, E.C.). México: Fondo de Cultura Económica.

" Larroyo, F. \& Escobar, E. (1971). Introducción a la filosofía de la cultura. México: Editorial Porrúa.

» Lemon, M. C. (2003). Philosophy of History. Londres/Nueva York: Routledge.

» Long, A. A. (1996). Stoic Studies. Nueva York: Cambridge University Press.

» Maritain, J. (1957). On the Philosophy of History. Nueva York: Scribner.

» Neher, A. (1972). La filosofía hebrea y judía en la Antigüedad. En El pensamiento prefilosófico y oriental. México: Siglo Veintiuno Editores.

» Ortiz, F. M. (2014). La Primera Guerra Mundial en la "filosofía de la historia" de Eric Hobsbawm a cien años de 1914. Mañongo, XXII (43).

» Ramírez, C. (2011). La hermenéutica de la historia y la importancia de explicar la historia mundial desde México. Co-herencia, 8 (14).

» Rohbeck, J. (2007). Por una filosofía crítica de la historia. Isegoría. Revista de Filosofía Moral y Política, 34, 63-79.

"Salles, R. (2014). Epictetus and the causal conception of moral responsibility and what is eph'hemin. En Destrée, P., Salles, R. y Zingano, M. (Eds.). What is Up to Us? Studies on Causality and Responsability in Ancient Philosophy. Sankt Augustin: Academie Verlag.

"Salles, R. (2012). Oíkzíwoıs in Epictetus. En Vigo, A. G. (Eds.). Oikeiosis and the Natural Basis of Morality. From Classical Stoicism to Modern Philosophy (pp. 95-120). Hildesheim-Zurich-New York: Georg Olms Verlag.

» Sandback, F. H. (1975). The stoics. Londres: Chetto \& Wind Ltd.

"Sellars, J. (2007). Stoic Cosmopolitanism and Zeno's Republic. History of Political Thought, XXVIII (1).

"Soroabji, R. (2000). Emotion and peace of mind, From stoic agitation to Christian temptation. Oxford: Oxford University Press.

" Tucker, A. (2009). A Companion to the Philosophy of History and Historiography. Singapore: Wiley-Blackwell.

"Vico, G. (2006). Principios de una Ciencia Nueva en torno a la naturaleza común de las naciones (trad. Carner, J.). México: Fondo de Cultura Económica.

» Von Mises, L. (1975). Teoría e historia. Madrid: Unión Editorial.

» Walsh, W. H. (1978). Introducción a la filosofía de la historia (trad. Florentino M. Turner). México: Siglo Veintiuno Editores.

» Wirth, G. (1986). Alejandro Magno. Barcelona: Salvat Editores. 